\title{
La monarquía castellana y los Staufer. Contactos políticos y diplomáticos en los siglos XII y XIII
}

\author{
Máximo Diago HeRnando
}

Los reinos de Castilla y León ocuparon una posición peculiar en el panorama político de la Europa medieval, que en gran medida fue resultado de su inicial desconexión con el imperio carolingio, y de la concentración de sus objetivos de expansión territorial hacia el sur, que les llevó a descuidar sus relaciones políticas con los territorios europeos ultrapirenaicos, con los que en contrapartida establecieron múltiples contactos ya desde fechas muy tempranas otros territorios peninsulares de los ámbitos navarro, aragonés y catalán.

Por su parte esta falta de interés por el establecimiento de contactos políticos con los territorios ultrapirenaicos, tuvo como contrapartida el que los monarcas castellano-leoneses persiguiesen desde muy temprano el objetivo de hacerse reconocer una cierta condición hegemónica en el territorio peninsular, el de la antigua Hispania. $Y$ este afán llevó a que en este ámbito político se desarrollase en estos siglos medievales una singular idea imperial, que pervivió hasta el siglo XIII, según Schramm hasta el momento en que Alfonso $X$ presentó su candidatura al imperio romanogermánico.

Teniendo en cuenta este contexto, presenta por consiguiente un notable interés analizar el proceso de establecimiento de contactos políticos y diplomáticos entre el reino castellano-leonés y el imperio germánico plenomedieval, tanto para seguir la trayectoria de incorporación del primer reino al mundo de la alta política europea, como para determinar si al entrar en contacto estas dos entidades políticas de tan distintas características se produjo un cierto choque de ideologías imperiales, o por el contrario el perfil imperial de la monarquía castellano-leonesa no fue percibido más allá de los Pirineos ni se intentó que lo fuese. 


\section{LOS PRIMEROS CONTACTOS DIPLOMATICOS DEL REINO CASTELLANO-LEONÉS CON EL IMPERIO ALEMÁN}

Aunque ya durante el reinado de Alfonso VI el reino castellano-leonés abandonó de forma decidida su tradicional política de aislamiento frente a la Europa transpirenaica, todavía tuvo que transcurrir bastante tiempo hasta que este periférico reino cristiano entró en contacto con el que en los siglos XI y XII fue el centro político que tuvo reconocido el rango hegemónico en todo el Occidente europeo, es decir el reino alemán, convertido desde el siglo $x$ en plataforma de revitalización de la idea imperial en el mundo europeo postcarolingio.

De hecho desde la coronación imperial de Otón I fueron exclusivamente príncipes de origen alemán los que, después de haber sido elegidos como monarcas del reino teutónico, consiguieron acceder a la dignidad imperial, aunque, como resulta bien sabido, no todos los que fueron reyes de Alemania en estos siglos tuvieron reconocida la condición de emperadores, porque varios no cumplieron con el requisito de hacerse coronar en Roma como tales '. En cualquier caso, al margen de esta cuestión de detalle, la superioridad de rango de los reyes alemanes en estos siglos plenomedievales era indiscutida en todo el ámbito occidental europeo, y la marginalidad y debilidad política de los monarcas castellano-leoneses se dejó advertir en el hecho de que desde Alemania no se sintió la más mínima necesidad de entrar en polémica con ellos por haber osado apropiarse un título, el de imperator, que se consideraba reservado para los monarcas de aquel territorio, que además eran reyes de romanos, y por lo tanto predestinados a recibir la corona imperial en Roma. Únicamente la noticia proporcionada por el padre Mariana, según la cual el emperador salio Enrique III se habría querellado ante el papa Víctor II porque el rey de Castilla Fernando I había adoptado indebidamente el título imperial, aportaría una prueba en contra de esta aseveración, pero su veracidad es dudosa, y de hecho no hemos encontrado ningún apoyo documental que la refuerce ${ }^{2}$, por lo que más bien cabe presumir que los reyes y emperadores alemanes del XI y gran parte del XII no concedieron ninguna atención al rincón castellano-leonés, y si llegaron a tener noticia de que sus reyezuelos se llamaban a veces emperadores no verian en dicha práctica

\footnotetext{
1 Una visión de conjunto sobre esta cuestión en R. FoLz, L'idée d'Empire en Occident du Ve. au XIVe siècle, París, 1953.

2 Valora la noticia que proporciona Mariana en De rebus Hispaniae, lib. IX, E. STEINDORFF, en Jahrbücher des Deutschen Reiches unter Heinrich III, Leipzig, 1881, vol. 2, p. 485.
} 
una amenaza al reconocimiento de su rango hegemónico, sino que la entenderían como manifestación de ciertas peculiaridades hispanas. $Y$ de hecho, si bien es cierto que desde la Europa transpirenaica nunca se tomaron en serio las pretensiones imperialistas de los reyes castellano-leoneses, sí que se les vino a reconocer con frecuencia la condición de únicos continuadores de la monarquía visigótica, al reservarles el calificativo de reges Hispaniae, con sus múltiples variantes ${ }^{3}$.

De entre todos los monarcas castellano-leoneses de la época que estamos analizando el que más lejos llevó sus ambiciones «imperiales» fue Alfonso VII, dado que, al margen de adoptar en la intitulación de la mayor parte de los documentos expedidos por su cancillería el título de imperator Hispaniae, con sus variantes ${ }^{4}$, llegó a hacerse coronar en 1135 en Santa María de León como emperador ${ }^{5}$. Este hecho sin embargo no levantó polémicas más allá de los Pirineos, sino que fue sistemáticamente ignorado, y ni la cancillería papal ni las de Conrado III o Federico I llegaron en ningún momento a reconocerle a Alfonso VII el título de imperator ${ }^{6}$, aunque en contrapartida algunos cronistas alemanes de la época sí se lo reconocieron indirectamente en algún momento, pero nunca de forma sistemática ${ }^{7}$.

Por lo demás, paradójicamente, el hecho de que Alfonso VII tuviese la osadía de hacerse coronar emperador, en lugar de contribuir a mantener la frialdad en las relaciones entre Castilla-León y Alemania, resultado de varios siglos de falta de contactos, vino a preparar el terreno para que el monarca castellano tomase la iniciativa de buscar, quizás por primera vez en la historia del reino de Castilla-León, el contacto político con los monarcas

\footnotetext{
3 Las referencias en las crónicas alemanas e italianas medievales a los reyes de Castilla y León como reges Hispaniae o reges Hyspanorum, entre otras variantes, son muy numerosas. Por ejemplo en la crónica de Federico I de Otón de Freising se califica a los embajadores que Alfonso VII había enviado a Conrado III "nuntios regis Hyspanorum». En los "Annales Colonienses Maximi» se Ilama a Beatriz de Suabia, esposa de Fernando III, "regina Hyspanie». En varias crónicas que refieren la disputa por la dignidad imperial entre Ricardo de Cornualles y Alfonso $X$, se identifica a este último como "Rex Castelle, qui et $Y$ spanie dicitur», y a veces como "Alfonso de Yspania".

4 Sobre las distintas intitulaciones adoptadas por Alfonso VII vid. P. Rassow, «Die Urkunden Kaiser Alfons'VII von Spanien» en Archiv für Urkundenforschung, 10 (1928), pp. 327-468, y 11 (1930), pp. 66-137.

5 Vid. M. Recuero Astray, Alfonso VII. Emperador. El Imperio hispánico en el siglo XII, León, 1979, p. 131.

6 Vid. W. KIENAST, Deutschland und Frankreich in der Kaiserzeit (900-1270). Weltkaiser und Einzelkönige, Stuttgart, 1975, vol. 2, p. 373.

7 W. KIENAST proporciona algunos ejemplos tomados de Rahewin y de los Anales de Cambrai (Éstos refiriéndose a Fernando II de León), en op. cit. p. 374. Vid. también E. HuEFFER, «Die leonesischen Hegemonie-bestrebungen und Kaisertitel» en Spanische Forschungen der Görresgesellschaft, 3 (1931), pp. 337-84.
} 
alemanes. En concreto así nos lo prueba una noticia de la crónica de Otón de Freising, que refiere cómo el rey Conrado III, primero de los monarcas alemanes del linaje Staufer, celebró la fiesta de la Pascua de Pentecostés en Coblenza el 27 de mayo de 1151, y poco después despidió desde esta misma ciudad renana a los embajadores del rey Alfonso VII, que volvieron a Castilla, después de haber permanecido en la corte del monarca alemán durante un tiempo relativamente largo ${ }^{8}$. El carácter extremamente escueto de la noticia cronística nos impide determinar con detalle cuál fue la misión de estos embajadores, y por qué su permanencia en tierras alemanas terminó resultando prolongada, pero en cualquier caso sugiere que la iniciativa para el establecimiento del contacto diplomático partió de Castilla-León, y que el monarca alemán, consciente de la superioridad de su rango en relación al del monarca hispano, mostraría escasa predisposición a atender con diligencia las propuestas de los embajadores.

En cualquier caso lo cierto es que el rey Conrado III apenas sobrevivió un año a los sucesos de Coblenza de mayo de 1151, y que poco después de su muerte, hacia fines de julio de 1152, su sobrino y sucesor Federico I despidió en Spira a su prima, la princesa Richilda de Polonia, que estando desposada con el rey Alfonso VII de Castilla-León, partió hacia tierras hispanas para reunirse con su futuro marido ${ }^{9}$. $Y$, por consiguiente, es muy probable que, a resultas de la estancia de los embajadores castellanos en la corte de Conrado III, se concertase este desposorio, que bien pudo responder al deseo de Alfonso Vil de vincularse por vía matrimonial con el linaje imperial de los Staufer, por razones de prestigio.

En efecto la princesa polaca que se convirtió en segunda esposa de Alfonso VII tenía sangre imperial en sus venas, por parte de su madre Agnes, que era hija del margrave de Austria Leopoldo III y de la princesa alemana Agnes, hija del emperador Enrique IV que estuvo casado en primeras nupcias con el duque de Suabia Federico I, que le dio entre otros hijos a Conrado III y al padre del emperador Federico I ${ }^{10}$. Por consiguiente

8 El texto de la crónica reza así: "Igitur proximum pentecosten in Confluentia, ubi et nuncios regis Hyspanorum iam diu secum moratos dimisit...", Ottonis Episcopi Frisigensis et Rahewini. Gesta Frederici seu rectius Cronica, Darmstadt, 1965, 1, ep. 69, p. 278 (Traducción al alemán en p. 279).

9 Vid. Wibaldi Epistolae, n 391 . En P. JAfFé (Ed.) Biblioteca Rerum Germanicarum, $t .1$. Monumenta Corbeiensia, Berlin, 1864, pp. 522-3. El texto reza así: «Transacta apud Ulmam curia, domnus rex Spiram procedet. Ibi neptim suam, a rege Hispanorum desponsatam et magnifice dotatam, in magno comitatu deferendam tradet".

${ }_{10}$ Vid. los cuadros genealógicos que ofrece O. EnGELS en Die Staufer. Stuttgart, 1994, 6a ed. Y E. BoshoF, Die Salier, Stuttgart, 1987, p. 341. 
la princesa Richilda resultaba ser biznieta por línea femenina del emperador salio Enrique IV, estando además emparentada tanto con los Staufer como con los Babemberger de Austria, de forma que, al casar con ella Alfonso VII pasó a quedar vinculado por lazos de parentesco con familias de un rango político muy superior al suyo, y pertenecientes a un ámbito geopolítico, el germánico-eslavo, con el que hasta entonces no se habían establecido desde Castilla-León contactos políticos ni diplomáticos. No obstante no dejaba de tratarse de un representante menor dentro del círculo de parientes de Conrado III y Federico I, en particular si tenemos en cuenta que era la hija de un duque polaco que vivía en el exilio en la corte del rey alemán ${ }^{11}$. Y a pesar de ello el esfuerzo diplomático que tuvo que realizar Alfonso VII fue notable, y las negociaciones debieron resultar muy laboriosas, ya que en primer lugar la estancia de los embajadores en la corte de Conrado III fue según la noticia cronística relativamente prolongada, y en segundo lugar el envío a Castilla de la elegida para esposa se demoró más de un año, resultando imposible a partir de las noticias de las crónicas determinar las razones de la demora.

Estas circunstancias vienen a reforzarnos en la impresión de que fue Alfonso VIl quien tomó la iniciativa, y demostró mayor interés en emparentar con el linaje imperial alemán, mientras que para los reyes alemanes este asunto no dejó de representar una cuestión secundaria. De hecho la concertación del matrimonio no vino a sancionar ninguna alianza política concertada para la defensa de intereses territoriales y estratégicos frente a terceros, ya que a tenor de lo que hoy sabemos sobre la constelación de relaciones de poder existente en la Europa del momento, no es fácil encontrar ámbitos de confluencia de intereses político-estratégicos del reino de Castilla-León por un lado y del Imperio alemán por otro. $Y$ en efecto no se dispone de datos documentales que prueben que Alfonso VII y Federico I colaborasen en alguna empresa política común a raíz del casamiento del primero con Richilda. Por el contrario bodo apunta a hacer pensar que el principal objetivo perseguido por Alfonso VII al buscar este enlace con la familia imperial alemana fue el del incremento del prestigio personal, que también animó los otros dos proyectos matrimoniales acometidos poco después de su boda con Richilda, a saber el de su hija Sancha con el rey Sancho de Navarra, y el de su otra hija Constanza con el rey Luis VII de Francia, recientemente divorciado de su primera esposa Leonor de Aquitania. $Y$ así lo puso ya en su momento de relieve $P$. Rassow en su

11 Vid. O. ENGELS, op. cit., pp. 43-4. 
detenido análisis de la documentación expedida por la cancillería de este monarca hispano, al advertir cómo en algunos documentos de su última época se encuentran unas fórmulas de intitulación que tratan de dar expresión a la dignidad imperial de Alfonso VII de una forma sumamente solemne, que recuerda modelos de la cancillería imperial, y que contiene referencias explicitas a los matrimonios de las dos hijas del rey con los monarcas navarro y francés ${ }^{12}$.

Más difícil resulta aventurar las razones que pudieron llevar a Conrado III a atender las solicitudes del monarca hispano, entregándole como esposa a su sobrina Richilda, y luego a Federico I a respetar lo concertado por su antecesor, aunque de nuevo conviene recordar que la notoria dilación de las negociaciones y de los trámites sugiere que del lado alemán no se manifestó en ningún momento un decidido interés por llevar adelante la empresa, quizás porque no se terminaban de advertir las ventajas que de su éxito podían derivar para la casa imperial alemana. En cualquier caso el hecho de que Alfonso VII se había atrevido a hacerse coronar emperador, mientras que en contrapartida Conrado III persistió hasta su muerte en su condición de rey de romanos y no llegó a ceñir en sus sienes la corona imperial, no parece que resultase un factor distorsionador en las negociaciones, aunque resulta prácticamente imposible determinar si pudo influir en el retraso del envío de la novia a Castilla, teniendo en cuenta que Conrado III tenía proyectado realizar el viaje a Roma y se vio obligado a irlo retrasando para atender a graves problemas de política interna alemana, hasta que finalmente la muerte vino a frustrar su proyecto ${ }^{13}$. Por supuesto no existen indicios suficientes para afirmar con seguridad que Conrado III retrasó a propósito el envío de Richilda a Castilla, en espera de ser coronado emperador, para que así no quedase ninguna duda sobre su superioridad de rango respecto a Alfonso VII, quien ya hacía varios años que habia recibido la corona imperial en León, si bien se trata de una hipótesis explicativa que tampoco se puede rechazar a priori, máxime si tenemos en cuenta que transcurrió un amplio espacio de tiempo entre el momento del retorno a Castilla de los embajadores, fines de mayo de 1151, y el inicio del viaje hacia este mismo reino de Richilda, a fines de julio de 1152.

Por otra parte cabe plantearse también la hipótesis de que a Conrado III le pudo interesar atender la solicitud de Alfonso VII, para ampliar su ámbito de influencia política y reforzar así su posición hegemónica en el

\footnotetext{
12 Vid. P. Rassow, «Die Urkunden..." 10 (1928), pp. 412 y ss.

13 Vid. W.BERNHARD1, Jahrbücher des Deutschen Reiches unter Konrad III. Berlin, 1975 (Según la ed. de 1883), pp. 887 y ss.
} 
ámbito de la Europa occidental, y luego en consecuencia poder rivalizar en cuestiones de precedencia con los emperadores bizantinos. De hecho Conrado III, a pesar de que su posición política tanto en el interior de Alemania como fuera de ella estuvo constantemente marcada por el signo de la debilidad, siempre procuró presentarse en su correspondencia con Bizancio como el "hombre fuerte» del Occidente europeo, titulándose Imperator Romanorum, aunque en rigor este título no le correspondía. Y para justificarse hacía ver a los bizantinos que todos los reyes de los principales reinos vecinos reconocían su posición hegemónica y le rendían pleitesía, aunque, como ha reconocido Kienast, todas estas aseveraciones constituían una manifiesta mentira diplomática ${ }^{14}$. En efecto, en una carta dirigida al emperador Juan Comneno en 1142, Conrado III le manifestaba que los reyes de "Francia», "Hispania», "Anglia», "Dania» (Dinamarca) y otros reinos próximos al Imperio «cottidiana legatione sua cum debita reverentia et obsequio nos frequentant, ad ea quae imperii nostri mandata sunt se prompta esse tan obsidibus quam sacramentis affirmantes» ${ }^{15} . \mathrm{Y}$, en su mayor parte, esto era falso, ya que la débil posición política de Conrado III en la propia Alemania, que no le permitió siquiera emprender el viaje a Roma a efectos de hacerse coronar emperador, mucho menos le ofrecía base suficiente como para imponer su voluntad política a los otros monarcas del entorno, y colocarles en una relación de estrecha dependencia hacia su persona. Por lo demás, en lo que las referidas aseveraciones afectan a Hispania, resultan particularmente deformadoras de la realidad histórica que la escasa documentación conservada nos permite entrever, puesto que no hay constancia de que Alfonso VII enviase legaciones diplomáticas con regularidad a Conrado III, y la única de la que tenemos noticia es la ya referida, cuyos miembros regresaron a Castilla en mayo de 1151; ni tampoco se dispone de la más mínima prueba de que el monarca castellano-leonés obedeciese orden ninguna procedente de Alemania, o participase en empresas políticas comunes con Conrado III, ni en posición de aliado, ni de subordinado. Pero, a efectos propagandísticos, el rey alemán pudo considerar conveniente aprovechar la oferta del establecimiento de un vínculo matrimonial por parte de Alfonso VII, después de que falleciese su primera esposa en 1149, para reforzar sus argumentos frente a Bizancio, sin ánimo en cualquier caso de inmiscuirse en los asuntos ibéricos, ni de buscar tampoco un aliado efectivo que colaborase con él en la persecución de sus objetivos políticos.

14 Vid. W. KIENAST, op. cit. t. II, pp. 334-5.

15 Ibid. Cita carta del 12-II-1142, a la que se refiere Otón de Freising en su Crónica, l, ep. 25. 
En suma, por consiguiente, pudieron ser exclusivamente razones de prestigio las que movieron a ambas partes a concertar la referida alianza matrimonial, y esta hipótesis queda corroborada por la constatación de que tras producirse el casamiento pasaron varias décadas hasta que volvieron a reanudarse los contactos políticos entre el Imperio alemán y los reinos de Castilla y León. La emperatriz Richilda sin embargo continuó siendo utilizada por su primo el emperador Federico I como instrumento al servicio de la consecución de determinados objetivos políticos, mucho más concretos por lo demás que los que inicialmente se persiguieron con su entrega como esposa a Alfonso VII. Y así, después de enviudar por primera vez a la muerte de éste, Richilda fue entregada en matrimonio por intervención de su primo en otras dos ocasiones, primero al conde de Provenza Raimundo 111, y tras enviudar de él, al conde de Tolosa Raimundo $V$, concertándose en los dos casos los matrimonios para sancionar alianzas políticas de Federico I con los respectivos príncipes elegidos como esposos, concertadas con el objetivo de afianzar su hegemonía en el sur francés, el cual fue perseguido con intensidad por el emperador después de su matrimonio con Beatriz de Borgoña en $1156{ }^{16}$.

\section{SEGUNDA ETAPA EN EL PROCESO DE ACERCAMIENTO CASTELLANO-ALEMÁN: LA NEGOCIACIÓN DEL MATRIMONIO DE LA INFANTA BERENGUELA CON CONRADO DE ROTHENBURG}

El matrimonio de Alfonso VII con Richilda de Polonia representó un hito importante en el proceso de "apertura» hacia el mundo europeo occidental del reino de Castilla-León, y contribuyó positivamente a realzar el rango de la familia real, que a partir de entonces multiplicó los vínculos matrimoniales con otras monarquías de su entorno, ya no exclusivamente hispanas, si tenemos en cuenta que una de las hijas de este monarca casó nada menos que con el rey Luis VII de Francia.

$Y$ en este contexto hay que explicar también el matrimonio del rey de Castilla Alfonso VIII con Leonor, hija del monarca inglés Enrique II, que inicialmente había estado proyectado que casase nada menos que con el

16 Vid. W. Georgl, Friedrich Barbarossa und die auswärtigen Mächte. Studien zur Aussenpolitik 1159-1180, Peter Lang, Frankfurt am Main-New York. Bern. París, 1990, pp. 49, y 71-2, en lo que se refiere al matrimonio con el conde de Provenza Raimundo III; y p. 145 en lo que toca al posterior matrimonio con el conde Raimundo $V$ de Tolosa. El conjunto de la obra ofrece interesantes consideraciones sobre la política borgoñona de Federico I. 
príncipe alemán Federico de Suabia ${ }^{17}$. El éxito diplomático de la monarquía castellana en este año de 1170 fue, pues, notable, ya que por un lado se consiguió establecer un vínculo matrimonial con una de las familias regias más poderosas de la Europa del momento, y precisamente con una princesa prometida a una familia de mucho mayor rango que la de los reyes de Castilla, como era la de los Staufer, y por otro lado se logró que del matrimonio derivasen ventajas políticas concretas para el reino de Castilla, dado que conllevó la concertación de una alianza que permitió al rey castellano intensificar la presión sobre el reino de Navarra, y abrió el camino para la conquista de la Rioja ${ }^{18}$.

De esta manera, cuando a fines de la década de 1180 , el emperador Federico I, que después de haber enviado a su prima Richilda a Alfonso VII al poco de haber comenzado su reinado, en 1152, apenas mostró interés por establecer contactos políticos con Castilla o León, volvió a prestar una cierta atención a estos reinos, para negociar el matrimonio de su hijo Conrado con la hija de Alfonso VIII, la infanta Berenguela, la situación habia cambiado mucho con respecto a la de mediados de siglo. $Y$ este cambio se había traducido muy en particular en una mayor presencia de Castilla en el escenario político europeo transpirenaico, manifestada en una intensificación de las relaciones diplomáticas con las monarquías francesa e inglesa.

Según P. Rassow, el emperador Federico I desarrolló una sistemática política matrimonial que fue concebida como un elemento más al servicio de su proyecto político global, de manera que la mayor parte de los vínculos matrimoniales proyectados o llevados a ejecución por este monarca alemán tuvieron por objeto reforzar alianzas políticas necesarias para la persecución de sus intereses estratégicos ${ }^{19}$. El proyecto de casar a uno de sus hijos varones, Conrado de Rothenburg, con la hija y presunta heredera del rey castellano Alfonso VIII, habría obedecido según este mismo autor también a motivaciones políticas, aunque a la hora de precisarlas de modo más concreto se tropieza con ciertas dificultades, y por ello él se limita a apuntar que fueron las relaciones de parentesco de Alfonso VIII con otros poderes europeos las que le convirtieron en figura mucho más influyente que la de un simple dinasta, y despertaron en Federico I el interés

17 Vid. W. GEORGI, op. cit., p. 256.

18 Vid. W. GeOrGI, op. cit., pp. 275 y ss. Analiza pormenorizadamente los motivos políticos que llevaron a las dos partes a la concertación del matrimonio.

19 P. Rassow, Der Prinzgemahl. Ein pactum matrimoniale aus dem Jahre 1188, Weimar, 1950, pp. 54 y ss. 
por buscar su alianza a través del establecimiento de un vínculo matrimonial que era desigual por cuanto el rango de la familia imperial de los Staufer era entonces notablemente superior al de la familia real castellana ${ }^{20}$. Sea esto o no cierto, la novedad más significativa que ofrecen estas negociaciones matrimoniales, iniciadas hacia mayo de 1187 , con respecto a las que protagonizaron Alfonso VII y Conrado III a comienzos de la década de 1150 , radica en que en esta ocasión la iniciativa partió del lado alemán, y ello constituye suficiente prueba para demostrar hasta qué punto se había incrementado en pocas décadas el prestigio del reino castellano en el contexto europeo.

Las peculiaridades del contrato matrimonial que entonces se firmó, y al que no pudo seguir una inmediata consumación del matrimonio porque la novia era todavía de corta edad, han sido analizadas exhaustivamente por P. Rassow en una conocida monografía ${ }^{21}$, y por ello no nos vamos a extender aquí en dar cuenta de ellas. Por el contrario sí que nos interesa detenernos en reflexionar sobre las razones que pudieron llevar a que finalmente el proyecto no prosperase, dado que su identificación nos puede ayudar a profundizar en la comprensión del sistema de relaciones políticas y diplomáticas establecido en Europa a fines del siglo XII, y del papel que las relaciones bilaterales entre Castilla y el Imperio alemán desempeñaban en el mismo.

En este punto la diversidad de opiniones es sin embargo notable, puesto que a la tesis tradicional que veía en el nacimiento a Alfonso VIII de un hijo varón en noviembre de 1189 como el factor determinante de la ruptu$\mathrm{ra}^{22}$, se han ido sumando otras varias. Y entre ellas habría que destacar por su originalidad la recientemente propuesta por Odilo Engels, quien enmarca la ruptura en un contexto político y diplomático muy amplio, y asigna a la ya anciana reina de Inglaterra, Leonor de Aquitania la principal responsabilidad en el asunto. En efecto, este autor considera que ésta acudió a comienzos de 1191 a visitar personalmente al emperador Enrique

20 Ibid. pp. 52-4.

21 P. Rassow, Der Prinzgemahl...

22 Valora como factor determinante de la ruptura del plan el nacimiento de un hijo varón a Alfonso VIII en noviembre de 1189, J. GonzáL.eZ, El reino de Castilla en la época de Alfonso VIII, t. I, Madrid, 1960, pp. 197-8. Sugiere que el desposorio celebrado en la curia de Carrión en junio de 1188 se basaba en la condición de heredera del trono castellano de Berenguela, y que al nacer un heredero varón Conrado de Rothenburg, que había vuelto a Alemania después de Carrión, porque Berenguela todavía era demasiado joven para consumar el matrimonio, ya no volvió a acordarse del compromiso, dado que ya no era previsible que se convirtiese en rey consorte de Castilla. 
VI, que hacía unos meses había sucedido a su padre Federico I, para proponerle que, si prometía guardar neutralidad en el conflicto franco-inglés, ella ultimaría la boda de su hijo el rey Ricardo, hasta entonces prometido con Adelaida, hermanastra del rey de Francia, con Berengaria de Navarra. La ventaja inmediata que Enrique Vl obtenía de este proyecto radicaba en que su puesta en práctica forzaría a Ricardo, entonces aliado con el principal adversario del emperador, Tancredo de Lecce, con quien se disputaba el trono siciliano, a abandonar Sicilia para prepararse ante un inminente conflicto con el rey de Francia, quien se preveía que se sintiese agraviado por el repudio de su hermanastra. Enrique Vl accedió, y a continuación la reina Leonor, sin manifestarle a él su propósito, habría partido a negociar en la curia romana la disolución del matrimonio de Berenguela de Castilla con Conrado de Rothenburg. Y por incitación suya terminaría el papa Celestino III enviando un cardenal a Castilla, quien se encargó de convencer a Berenguela para que manifestase su aversión personal hacia el marido que se le había elegido, lo cual podía resultar creíble, teniendo en cuenta el desarreglado carácter que se ha atribuido a Conrado. Y gracias a esta declaración se habría podido disolver el matrimonio, puesto que el derecho canónico disponía que para que éste fuese válido era necesario el consenso explícito de la novia en el momento en que alcanzaba la edad para poder llevar a efecto la consumación matrimonial ${ }^{23}$.

Los intereses particulares de la monarquía inglesa, que buscaba un aislamiento de la alianza de los Staufer y de los Capetos, para poder defender mejor sus posesiones en el continente, habrían determinado por consiguiente el fracaso de este proyecto matrimonial. $Y$ de hecho, admitiendo que esta hipótesis explicativa sea correcta, no sería entonces la única ocasión en que la anciana reina inglesa Leonor, madre de la homónima reina castellana, esposa de Alfonso VIII, se inmiscuía en asuntos internos de la familia real castellana para llevar adelante proyectos políticos que eran totalmente ajenos a los intereses del reino de Castilla, poniendo así de manifiesto cómo este último no había alcanzado todavía la madurez necesaria para seguir una política diplomática propia en el continente europeo.

En efecto una ocasión en que un miembro de la familia real castellana fue utilizado como pieza para sellar un acuerdo diplomático de reconciliación entre Francia e Inglaterra, que en nada afectaba de forma directa a los intereses del reino de Castilla, se presentó en el año 1200, cuando se

23 O. Engels, Die Staufer..., pp. 127 y ss. 
negoció la boda de la infanta Blanca, hija como Berenguela de Alfonso VIII y de Leonor Plantagenet, con el primogénito del rey de Francia, el futuro rey Luis VIII. Este matrimonio fue negociado entre los reyes inglés y francés, Juan sin Tierra y Felipe II Augusto, interviniendo también de forma muy activa la madre del primero, la reina Leonor, y con el mismo se trataba de sancionar el acuerdo de paz alcanzado entre ambos monarcas. Las fuentes no indican en ningún momento que se contase con la anuencia del rey de Castilla, aunque sí hacen constar que la reina Leonor en persona, a pesar de su avanzada edad, emprendió viaje al reino castellano para recoger a su nieta, la novia, y así asegurarse que el proyecto matrimonial se llevaba rápidamente a efecto, pues ella tenía un gran interés en que el tratado de paz prosperase. Quizás su presencia en tierras castellanas resultó determinante para que el rey Alfonso VIII accediese a entregar a su hija para un proyecto matrimonial que ciertamente era ventajoso, pues prometía a ésta poder alcanzar la corona francesa, como de hecho así fue, pero que no respondía a intereses diplomáticos o estratégicos concretos de la Castilla del momento ${ }^{24}$. $Y$ en cualquier caso, si admitimos la hipótesis de Engels sobre las razones de la ruptura del matrimonio de la infanta Berenguela con Conrado de Rothenburg, no deja de llamar la atención hasta qué punto la reina de Inglaterra y duquesa de Aquitania manejó los hilos diplomáticos que determinaron la suerte de los matrimonios de sus nietas castellanas, como si el padre de éstas, el propio rey Alfonso VIII, no tuviese autoridad y prestigio suficiente para moverse en el escenario político europeo y poder utilizar los matrimonios de sus hijas para la consecución de proyectos políticos o diplomáticos propios.

\section{LA CONCERTACIÓN DEL MATRIMONIO DE FERNANDO III CON BEATRIZ DE SUABIA}

Por ironías de la historia, Berenguela, la infanta castellana que había sido desposada con Conrado de Rothenburg y que había solicitado la disolución del matrimonio alegando aversión personal hacia el novio, fue la que bastantes años más tarde quiso que su primogénito Fernando, rey de

\footnotetext{
24 Proporciona algunas noticias sobre las negociaciones que llevaron a la boda de Luis de Francia con Blanca de Castilla Mateo París en su Crónica Mayor, en Rerum Britannicarum Medii Aevi. Scriptores (Rolls Series), 57, II, p. 461 (Año 1200). Para encuadrar el episodio en el marco de la evolución de las relaciones entre el papa, Alemania, Francia e inglaterra, vid. T. HoLzAPFEL, Papst Innozenz III, Philipp II. August von Frankreich und die englisch-welfische Verbindung $1198-$ 1216, Peter Lang, Frankfurt-Bern-New York-París, 1991, pp. 47 y ss.
} 
Castilla y heredero del reino de León, contrajese matrimonio precisamente con una sobrina de Conrado, la hija del hermano menor de éste, Felipe, quien le había sucedido en el ducado de Suabia a su muerte en $1196{ }^{25}$.

De hecho Felipe de Suabia, por ser el hijo más joven de todos los del emperador Federico I, había sido inicialmente destinado a la carrera eclesiástica, llegando a ser elegido para obispo de Würzburg en 1190. Su hermano mayor el emperador Enrique VI pronto preparó para él sin embargo un futuro muy distinto, al hacerle casar con la princesa bizantina Irene, quien se encontraba en Palermo, preparada para casar con un hijo de Tancredo de Lecce, cuando Enrique VI conquistó esta capital siciliana. Era esta princesa hija del emperador bizantino Isaac Angelos, y con ella tuvo Felipe de Suabia cuatro hijas, de las cuales una, Kunigunda, casó con el duque Wenceslao I de Bohemia, y otra, María, con el duque Enrique II de Brabante. A las otras dos hijas las fuentes coinciden en llamarlas a ambas Beatriz, dando así lugar a una cierta confusión a la hora de su identificación, como veremos ${ }^{26}$.

Felipe de Suabia ha pasado sin embargo a la historia por haber sido el candidato del linaje Staufer que, a la muerte de su hermano mayor Enrique VI en 1197, se disputó la sucesión al imperio y al propio reino de Alemania con el candidato güelf́o Otón IV de Brunswick. Precisamente cuando ya parecía anunciarse su victoria sobre este último, el conde palatino Otón de Wittelsbach le asesinó en Bamberg el 21 de junio de 1208, al parecer para vengarse porque Felipe le habia prometido en matrimonio a su hija menor Beatriz, presumiblemente la que finalmente casó con Fernando III de Castilla, y luego ésta había pasado a ser prometida a un sobrino del papa Inocencio III ${ }^{27}$.

Tras la muerte de Felipe el camino hacia el trono imperial se allanó para Otón IV, y además, para congraciarse con el partido contrario, consiguió nada menos que contraer matrimonio con la hija mayor de Felipe, de nombre Beatriz, distinta de su homónima convertida luego en reina de

25 Sobre Conrado de Rothenburg y su hermano Felipe como duques de Suabia, vid. Ch. F. STAELIN, Wirtembergische Geschichte, T. II, Schwaben und Südfranken. Hohenstaufenzeit 10801268, Stuttgait-Tübingen, 1847 , pp. 123 y ss.

${ }_{26}$ Vid. E. WINKELMANN, Jahrbücher zur Deutschen Geschichte unter Philipp von Schwaben, Leipzig, 1873. Y Jahrbücher... unter Otto IV. von Braunschweig, Leipzig, 1878. O. Engels en Die Staufer... propone que Felipe de Suabia tuvo tres hijas con el nombre de Beatriz, de las cuales una murió en 1208. A la Beatriz que casó con Fernando Ill algunos autores la llaman Isabel.

${ }_{27}$ Esta es la explicación que propone E. WINKELMANN, en Jahrbücher... unter Philipp... pp. 436,458 y 536 y ss. Una visión sintética sobre los problemas del reinado de Felipe de Suabia en O. Engel.s, Die Staufer... pp. 140 y ss. 
Castilla. Según Winkelmann, a raíz de la concertación de este matrimonio en 1209, las dos hijas de Felipe de Suabia que llevaban el nombre de Beatriz habrian pasado a quedar bajo la tutela de Otón IV, mientras que las otras dos hermanas ya habrían sido entregadas a sus respectivos maridos, aunque no tuviesen todavía edad para consumar los matrimonios ${ }^{28}$. Por esta vía la que sería con posterioridad reina de Castilla y León pasaría en su más tierna edad a poder güelfo, permaneciendo en esta situación hasta las vísperas de ser enviada a Castilla para casarse en el año 1219.

En efecto, según propone Winkelmann, las dos hijas de Felipe de Suabia habrían sido enviadas por Otón IV, antes de partir éste hacia su campaña italiana, a su ciudad de Brunswick (Braunschweig). Allí se produciría la muerte de la mayor, la esposa de Otón IV, que falleció antes que su marido. Éste por su parte, después de la derrota de Bouvines del 27 de julio de 1214, tuvo que retirarse hacia sus posesiones patrimoniales mientras su rival, el joven Federico II, se hacía con el poder en Alemania, muriendo en el Harzburg en 1218. Entre tanto la joven Beatriz debía seguir en poder güelfo, después de la muerte de Otón presumiblemente bajo la tutela del hermano de éste Enrique de Brunswick ${ }^{29}$.

Es prácticamente seguro por consiguiente que cuando los embajadores castellanos llegaron a la corte de Federico ll a buscar una esposa para el joven rey Fernando III, Beatriz de Suabia no se encontraba todavía en poder de su primo, el joven monarca alemán, entonces aún rey de romanos. Este hecho no ha sido advertido por muchos autores, sobre todo españoles, que se han ocupado de analizar este episodio diplomático ${ }^{30}$, pero quizás contribuya a explicar por qué los embajadores castellanos se demoraron tanto en las negociaciones, que según algunos se prolongaron durante al menos cuatro meses ${ }^{31}$.

28 E. WINKELMANN, Jahrbücher... unter Otto... pp. 127 y ss.

29 Beatriz, la mujer de Otón IV, murió en 1212, y éste el 19-V-1218. La tesis de que Beatriz siguió en poder güelfo la mantiene E. WINKELMANN; op. cit. y Jahrbücher zur Deutschen Geschichte unter Friedrich II, T. I, 1889, pp. 22-3.

so Por ejemplo C. J. SocarRas da por supuesto que Beatriz residía en la corte imperial cuando los embajadores castellanos enviados por Berenguela en 1218 acudieron a la misma. En Alfonso $X$ of Castile: A study on Imperialistic Frustration, Barcelona, 1976. Julio GonzÁLEz por su parte también reflexiona sobre los motivos de la prolongación de las negociaciones, pero no apunta la posibilidad de que Beatriz no se encontrase en la Corte. Vid. Reinado y Diplomas de Fernando III, vol. I, Córdoba, 1980, pp. 96-101.

31 Las principales noticias a este respecto las proporcionan Jiménez de Rada y la Crónica Latina, en quienes se basa preferentemente Julio GonzÁlEZ. También la obra clásica de Miguel DE Manuel Rodríguez, Memorias para la vida del Santo Rey Don Fernando 1II, Barcelona, 1974 (Reproducción del original de Madrid, 1800), p. 26. Señala que las negociaciones se prolongaron 4 meses y que tuvieron lugar en Norimberga (Nürnberg). 
La identidad de estos embajadores enviados por Berenguela a la corte de Federico II no se ha podido establecer con absoluta precisión ${ }^{32}$, pero no cabe duda de que se reclutaron entre eclesiásticos de alto rango, y que su misión fue valorada en Castilla como una de alta importancia, y por tanto merecedora de sustanciosas recompensas ${ }^{33}$. Ello da idea de hasta qué punto la iniciativa en esta ocasión, al igual que ocurrió en tiempos de Alfonso VII, partió de Castilla, que buscaba el establecimiento de alianzas matrimoniales con los Staufer por el prestigio que podían aportar a la casa real castellana.

De hecho resulta difícil determinar cuáles pudieron ser los motivos que llevaron a Berenguela a tratar de volver a emparentar con el linaje imperial alemán, y, advirtiendo esta dificultad, Socarras se ha atreviso a formular la pintoresca hipótesis de que le movió el deseo de desafiar simbólicamente a la memoria del papa inocencio III, que había sido el responsable de la anulación de su matrimonio con Alfonso IX de León ${ }^{34}$. Más probable es que le moviese el afán de incrementar el prestigio personal de su hijo, que entonces sólo era rey de Castilla, haciéndole emparentar con los dos linajes imperiales de la Europa del momento, el alemán y el bizantino, pues no se debe olvidar que Beatriz de Suabia era nieta tanto del emperador Federico I Barbarroja, como del emperador bizantino Isaac II Angelos.

No parece que cuando los embajadores castellanos partieron hacia la corte de Federico II se hubiese ya tomado la determinación en la corte castellana de cuál debería ser la futura esposa de Fernando III, y probablemente fue el monarca alemán quien les propuso a su prima Beatriz, si bien, por el hecho de que ésta no se encontraba en su poder, hubo que retrasar un cierto tiempo la ultimación del acuerdo diplomático. En efecto, es muy probable que Beatriz fuese directamente entregada a Federico II

32. La mayoría de los autores afirman que los embajadores fueron el obispo Mauricio de Burgos, el abad Pedro de San Pedro de Arlanza, el abad Rodrigo del monasterio de Ríoseco, y el prior de la Orden de San Juan, Pedro Odoardo. Estos nombres propone por ejemplo M. DE MANUEL Rodriguez, op. cit., p. 26. Por un documento de la colección diplomática de San Zoil de Carrión consta que fue a Alemania a buscar a la princesa Beatriz el prior de este monasterio y camerario de España, Don Juan. Vid. Ma L. PALAcio SÁnchez-Izoulerdo, Colección Diplomática del monasterio de San Zoil de Carrión (Siglos XI al XV), Universidad Complutense, Madrid, 1988, p. 181.

33 En concreto al prior de Carrión le concedió un privilegio Fernando 11 en 1220 con motivo del «gratissimi servicii quod vos lohannis prior Carrionis et Hyspanie Camerario eundo in Alamaniam pro legitima uxore mea regina Beatrice filia Philippi quoddam regis Romanorum". Vid. $M^{a}$ L. PALACIO SÁnCheZ-IZQUIERDO, op. cit., p. 181 (EI documento original en AHN, Clero, carpeta 1702-6).

34 C. J. SOCARRAS, op. cit, p. 102. 
con ocasión de la reconciliación de éste con el güelfo Enrique de Brunswick en el Reichstag celebrado en Goslar en el día de San Juan de 1219, cuando este último le entregó también las insignas imperiales, que había pasado a controlar tras la muerte de Otón IV, producida en mayo del año anterior ${ }^{35}$. A este respecto las crónicas apenas arrojan información, y lamentablemente sólo contamos con una noticia de los Annales Spirenses que refieren que en el año del señor de 1219 "Filia regis Philippi tradita fuit nuptui regi Hyspanie et traducta» ${ }^{36}$. Pero, aunque no se disponga de ninguna prueba definitiva para confirmarlo, es bastante probable que, dado que los desponsorios se celebraron en Burgos en noviembre de 1219, Beatriz, después de haberse llegado ya a un acuerdo con los embajadores castellanos para que ella fuese la futura esposa de Fernando III, fue entregada a su primo Federico II en junio de 1219 con motivo de la reconciliación de éste con Enrique de Brunswick, entendiendo que tanto ella como las insignias imperiales habían sido hasta entonces "rehenes» en manos de este príncipe güelfo ${ }^{37}$.

En cualquier caso estas negociaciones con la corte castellana debieron representar un asunto más bien secundario en la escala de prioridades de Federico II en aquellos momentos, y si la concertación del matrimonio fue aprovechada para el establecimiento de una alianza política duradera entre las dos monarquías, no hay constancia de que ésta se tradujese, al menos en las primeras décadas que siguieron a 1219, en fórmulas de colaboración con resultados apreciables. En este sentido el matrimonio de Beatriz de Suabia con Fernando III presenta bastantes paralelismos con el de Alfonso VII y Richilda de Polonia, por cuanto ninguno de los dos conllevaron a corto plazo una intensificación de los contactos políticos con el imperio, ya fuese en Alemania, Italia o Borgoña. A medio plazo sin embargo el matrimonio con Beatriz de Suabia estuvo cargado de consecuencias para la casa real castellana, y la incorporación de varios de sus miembros al mundo de la gran politica europea del siglo xIII, que todavía continuaba teniendo sus protagonistas principales en el papado y el imperio, hasta la caída de los Staufer, que favoreció la adquisición de un nuevo protagonismo por la monarquía francesa.

Paradójicamente las noticias sobre contactos diplomáticos entre la monarquía castellana y Federico li se multiplican en el período que sigue a la

35 Vid. E. Winkelmann, Jahrbücher,.. unter... Friedrich II..., t. 1, pp. 22-3.

36 Annales Spirenses, en Monumenta Germaniae Historica. Scriptores, t. XVII, p. 84.

37 Sostiene que los desponsorios se celebraron en Burgos el 27-X1-1219, M. DE MANUEL Rodfiguez, op. cit., p. 26. E. WINKELMANN acepta sin embargo como fecha de la boda el $31-1-1220$. Vid. Jahrbücher... unter... Friedrich II..., p. 22-3. 
muerte de Beatriz de Suabia, sobrevenida el 5 de noviembre de 1235, mientras que para el período anterior tan sólo hemos llegado a localizar en las fuentes documentales consultadas una, que refiere el envío por Beatriz, poco tiempo antes de su muerte, a su primo Federico de unos embajadores que le llevaron como presentes unos hermosos caballos y muy buenos regalos. En concreto la noticia la proporcionan los Annales Colonienses Maximi, que se expresan en estos términos:

«lbidem nuncii regine Hyspanie affuerunt, qui pulcherrimos dextrarios et magnifica munera cesari attulerunt. Nec multo post eiusdem regine mors est nunciata imperatorii, unde plurimum doluit, quia patruelis eius fuit» 38 .

Lamentablemente la fuente no aclara qué misión llevaban estos embajadores, y mucho más difícil resulta llegar a determinar si su envío por parte de Beatriz pudo estar motivado por el hecho de que ésta sintiese próxima su muerte, y quisiese asegurar a sus hijos una cierta participación en su «herencia alemana». No obstante la mayor parte de las noticias documentales disponibles apuntan en este sentido, demostrando que la intensificación de los contactos entre la casa real castellana y los Staufer a partir de la segunda mitad de la década de 1230 fue inicialmente el resultado del afán demostrado por parte de varios miembros de la primera de hacer "carrera política» en el ámbito del imperio, amparándose en su condición de herederos de Beatriz de Suabia.

\section{EL PROBLEMA DE LA HERENCIA DE BEATRIZ DE SUABIA Y LA MARCHA A ITALIA DEL INFANTE FADRIQUE}

La cuestión de determinar qué derechos correspondian a Beatriz de Suabia como hija del rey de rornanos Felipe, a su vez duque de Suabia, teniendo en cuenta que éste no había dejado ningún heredero varón, resulta muy difícil de resolver. $Y$, dado que las crónicas no nos informan sobre las condiciones en que los embajadores castellanos negociaron con Federico II el matrimonio de ésta con el rey castellano, no podemos afirmar si entonces se le prometió alguna dote que incorporase bienes y derechos en territorio alemán.

38 Annales Colonienses Maximi, en Monumenta Germaniae Historica, Scriptores, t. XVII, p. 845. Hay que llamar la atención sobre el hecho de que al recibir la embajada castellana en 1235 hacía pocos meses que Federico II había llegado a territorio alemán, para sofocar la rebelión de su hijo primogénito el rey Enrique. 
Algunos autores afirman sin inconvenientes que lo que estaba en disputa era el ducado de Suabia, atribuyendo a Beatriz un derecho al mismo que bajo ningún concepto le podía corresponder, ya que el ducado no constituía un bien patrimonial ni del linaje de los Staufer ni del rey Felipe, sino que era un feudo del imperio ${ }^{39}$, al margen de que Beatriz tenía otras dos hermanas mayores que ella, casadas en Bohemia y Brabante, las cuales, en caso de que el ducado hubiese sido transmisible en herencia a mujeres, habrían tenido mayor derecho al mismo que ella. Por lo demás ya a fines de 1216 o comienzos de 1217, es decir antes de la concertación de la boda con Fernando III, Federico II había nombrado duque de Suabia a su primogénito Enrique, por lo que no cabe pensar que Beatriz pudiese alimentar el deseo de que alguno de sus hijos se convirtiese en duque ${ }^{40}$. $Y$ que por su parte Federico II nunca tuvo en mente que algún infante castellano llegase a ocupar el ducado que desde hacía tanto tiempo se encontraba en poder de los Staufer, lo prueba el que en 1237, muerta ya su prima Beatriz, y caído en desgracia su hijo primogénito el rey Enrique, al tener lugar la elección de su segundo hijo Conrado como rey de romanos, se procedió simultáneamente a su nombramiento como duque de Suabia ${ }^{41}$.

Si Felipe de Suabia no podía por consiguiente disponer de su ducado para transmitirlo en herencia a sus hijas, sí que contaba sin embargo con un conjunto de bienes patrimoniales situados preferentemente en el ámbito territorial suabo, a los que éstas podian alegar derechos. La temprana muerte de este monarca dejó a sus herederas no obstante en una difícil situación de cara a salvaguardar la herencia paterna, y los autores, a falta de informaciones precisas en las fuentes documentales, no se ponen de acuerdo sobre cuál fue la suerte que siguió ésta. Winkelmann presume que la mayor parte del patrimonio de las hijas de Felipe, que estima que comprendía ai menos 350 castillos con sus derechos y territorios anejos, quedó en manos de Otón IV a raíz de casar con Beatriz, la mayor ${ }^{42}$, pero no aclara qué sucedió con este patrimonio tras la muerte de su esposa en

39 Vid. H. MaURER, Der Herzog von Schwaben. Grundlagen, Wirkungen und Wesen seiner Herrschaft in ottonischer, salischer und staufischer Zeit, Sigmaringen, 1978, pp. 269 y ss. Sobre la sucesión femenina en el derecho feudal alemán vid. G. VAN DER VEN, Die Entwicklung der weib/ichen Erbfolge im deutschen Lehensrecht, Marburg/Lahn, 1949 (Tesis doctoral mecanografiada).

to Vid. H. Maurer, op. cit., p. 274.

41 Ibid. p. 275. No resulta por consiguiente creible que Federico II hubiese prometido el ducado de Suabia al infante Fadrique de Castilla, como sostiene C. J. SocarRas, op. cit., pp. 143-4.

42 E. WINKELMANN, Jahrbücher... unter Otto... pp. $128-9$ y p. 161. Este autor considera que para 1208 ya estaban ultimados los matrimonios con los prínciples de Brabante y Bohemia, y probablemente ya entregadas las novias, si bien Otón IV no buscó llegar a un acuerdo con ellos sobre el reparto de la herencia porque entonces estos príncipes eran enemigos suyos. 
1212, y sobre todo tras su derrota en Bouvines en 1214. Presumiblemente estos bienes pasaron a manos del victorioso Federico II, quien consta que se mostró dispuesto a ceder parte de los mismos para contribuir a las dotes de sus primas. En concreto en 1215 aprobó la donación de la iglesia de Esslingen a María, casada con el duque de Brabante ${ }^{43}$, y de nuevo en 1235 pagó 10.000 marcos al rey de Bohemia, casado con Kunigunda ${ }^{44}$. Es probable por consiguiente que también a Beatriz le prometiese Federico ciertos bienes al concertar su matrimonio en 1219, y éstos serían los que al parecer ella deseaba que heredase su hijo Fadrique, quien ya por virtud de la elección del nombre parecía predestinado para hacer "carrera política" en Alemania, pues no hay que olvidar que Fadrique era una castellanización de "Friedrich", el nombre preferido por los Staufer para sus primogénitos ${ }^{45}$.

Diversos autores clásicos y modernos han afirmado que Fernando III solicitó reiteradamente a Federico II que restituyese los bienes correspondientes a la herencia de Beatriz de Suabia a su hijo Fadrique ${ }^{46}$, y algunos incluso han interpretado el envío por el monarca castellano al emperador alemán de tropas en el año 1238 para reforzar el ejército con el que este último luchaba contra las ciudades lombardas, como una medida dirigida a tratar de convencerle para que entregase a Fadrique los bienes que le correspondían por la herencia de su madre ${ }^{47}$. No obstante llama la atención que, habiendo muerio Beatriz en 1235, Fernando III esperase hasta el año 1239 para enviar a su hijo Fadrique ante el emperador a efectos de recibir la herencia materna, que por lo demás debía comprender bienes radicados en Alemania, y más en concreto en Suabia, cuando Federico II se encontraba entonces totalmente absorbido por los asuntos italianos.

En concreto las primeras noticias sobre la intención de enviar a Fadrique a la corte imperial las proporcionan dos cartas fechadas en

43 Vid. J. F. BOEHMER, Regesta Imperii, V, n 825. Una valoración de esta noticia documental en H. NIESE, Die Verwaltung des Reichsgutes im 13. Jahrhundert, Innsbruck, 1905, p. 6.

44 J. F. BOeHMer, Regesta Imperii, V, $\mathrm{n}^{\circ} 2.115$.

45 Sobre la importancia del nombre «Friedrich" para los Staufer vid. O. EnGELS, Die Staufer... pp. 9 y ss.

${ }_{46}$ Vid. entre las obras clásicas la de F. SCHIRRMACHER, Die letzten Hohenstaufen, Göttingen, 1871 , p. 141

${ }_{47}$ Vid. W. W. KiENAST, Deutschland und Frankreich... vol. 3, p. 608. También su obra Die deutschen Fürsten im Dienste der Westmächte bis zum Tode Philipps des Schönen von Frankreich, Utrecht, 1931, p. 86. La carta del emperador al rey de Castilla solicitándole tropas para luchar contra los lombardos en Monumenta Germaniae Historica, Constitutiones, t. II, doc. $n^{\circ}$ 206. Cartas similares se enviaron a los reyes de Hungria, Inglaterra y Francia. Noticias cronísticas confirman que en 1238 auxiliaron a Federico II soldados ingleses, franceses y españoles. Pero KIENAST llama la atención sobre el hecho de que Jaime I de Aragón se alió con los enemigos de Federico II. Vid. Die deutschen Fürsten... p. 86. 
Burgos el 4 de diciembre de 1239 que Fernando III envió al papa Gregorio IX, por las que trataba de interceder en el conflicto que éste mantenía con el emperador, y en una de las cuales le comunicaba que enviaba a su hijo Fadrique a la corte de Federico II, y le solicitaba ayuda y protección para éste en el caso de que su tío se negase a entregarle los bienes de la herencia materna ${ }^{48}$. Acompañando a Fadrique iba el abad Guillermo de Sahagún, quien en su misión diplomática también fue provisto de una carta credencial dirigida por la reina Berenguela al papa ${ }^{49}$, y una vez llegado a su destino logró una rápida promoción en la corte papal, donde fue elegido como cardenal en $1244{ }^{50}$. Fadrique sin embargo no llevaba el mismo destino que él, y es incluso probable que no llegase a tener ningún contacto con la curia papal. En efecto a principios del año 1240 Fadrique era recibido por el emperador en Foggia ${ }^{51}$, y el 25 de abril de este mismo año este último escribía una carta a Fernando III agradeciéndole el haber enviado a su hijo a la corte imperial para que así la muerte de su madre no fuese causa de que se rompiese el vínculo existente entre las dos familias ${ }^{52}$. De hecho este envío simultáneo del abad de Sahagún y del infante Fadrique a Italia en unos momentos particularmente graves para la vida política de esta península, debido a la reciente excomunión de Federico II por Gregorio IX, y con un destino diferente, nos viene a poner de manifiesto el interés de Fernando III por mediar en este grave conflicto que amenazaba con convulsionar a toda Europa, siguiendo así el ejemplo del cada vez más prestigioso monarca francés Luis IX ${ }^{53}$. En efecto tanto el francés como el castellano procuraron en todo momento intentar convencer al papa para que buscase la reconciliación con el emperador excomulgado, y ninguno de ellos llegó a romper sus relaciones con éste. En concreto por lo que se refiere a Fernando III, las varias cartas que Federico II le escribió hasta el mismo año de su muerte, en 1250 , es decir ya cinco años después de haber sido depuesto en el concilio de Lyon, demuestran hasta qué punto este último veía en el primero

48 Regesto de las cartas y referencias de procedencia en J. F. BOEHMER, Regesta Imperii, V, $n^{\circ} 11.237$ y 11.238 .

49 Ibid. $n^{2}$ 11.239. Carta fechada en Burgos, 5-X|l-1239.

so Sobre el abad Don Guillermo 111 de Sahagún, a quien también utilizó el papa como embajador ante el emperador vid. E. MARTinez LIÉBANA, El dominio señorial del monasterio de San Benito de Sahagún en la Baja Edad Media (Siglos XII-XV), Madrid, 1990, pp. 616-7.

${ }^{51}$ La noticia la proporciona la Ryccardi de Sancto Germano Notarii Chronica, en Monumenta.. Scriptores, t. XVIII, p. 379. "Eodem mense filius regis Castellae ad imperatorem aput Fogiam venit».

52 Regesto de la carta de Federico II de 25-IV-1240 en J. F. BoeHMER, Regesta Imperii, V, $n^{2} 3.020$.

53 Vid. J. RICHARD, Saint Louis, Paris, 1983. 
un fiel aliado ${ }^{54}$. Y la presencia del infante Fadrique en la corte imperial durante varios años a partir de 1240 pudo inicialmente contribuir a reforzar las buenas relaciones entre los dos monarcas, si bien algunos indicios apuntan a hacer pensar que este aventurero personaje no permaneció en la corte de su pariente el emperador en calidad de embajador al servicio de los intereses políticos castellanos, sino que más bien buscaría hacer su propia carrera, llegando en ocasiones a tomar decisiones de gran trascendencia, como por ejemplo la del propio abandono de la causa del emperador, sin contar en absoluto con la aprobación de la corte castellana.

En cualquier caso, a pesar de que Fernando III insistía en sus cartas al papa que el motivo del envío del infante Fadrique a Federico II era reclamar la herencia que le correspondía de su madre, no parece que tras la llegada de éste a Foggia a comienzos de 1240 se negociase apenas sobre este asunto, y mucho menos que se consiguiese alguna concesión de bienes en Suabia de parte del emperador. $Y$ teniendo en cuenta este hecho llama todavía más la atención que, en lugar de producirse una rápida ruptura entre ambas partes, Fadrique permaneciese junto a su tío el emperador algo más de cinco años, según testimonian las numerosas actas de su cancillería expedidas entre 1240 y 1245 en las que se menciona su presencia como testigo de la acción documental ${ }^{55}$.

Más bien cabe pensar que el verdadero objetivo del viaje de Fadrique a la corte imperial fue el de hacer "carrera política» en ésta, en la confianza de que la cercanía al emperador sería garantía de una pronta obtención de feudos u otros bienes territoriales en el imperio. Y así al menos parece sugerirlo la carta escrita por Federico II a Fernando III en septiembre de 1240 , en la que además de informarle de los éxitos obtenidos en la campaña contra Faenza, le comunica que su hijo se encuentra bien y al mismo tiempo se compromete a que velará por su educación y enriquecimiento ${ }^{56}$. Ciertamente cabe interpretar esta carta como una excusa por no haber entregado inmediatamente a Fadrique los bienes de la herencia materna

\footnotetext{
54 Referencias y regestos de estas cartas en J. F. BOEHMER, Regesta Imperii, V, n² 2.465 (Carta de 14-VIII-1239); $n^{\circ} 3.020$ (Carta de 25-IV-1240); no 3.146 (Carta de 23-IX-1240); $n^{\circ} 3.491$ (Carta de julio-1245) y $n^{0} 3.819$ (Carta de mayo de 1250 en la que lamenta y denuncia que el papa no cesa de procurar su perdición). Varias de estas cartas fueron editadas por J. L. A. HuILLARDBreholles, Historia Diplomática Friderici Secundi, t. V, París, 1857, y T. VI, París, 1860.

55 Vid. los vols. $V$ y VI de J. L. A. HuILLARD-BREHOLLES, op. cit. Y también las referencias que proporciona J. F. BOEHMER en Regesta Imperii, V. El último documento de la cancillería imperial en que el infante Fadrique aparece en las listas de testigos está fechado en Verona el 4-VI-1245. Vid. J. L. A. Huillard-Breholles, op. cit., t. VI, p. 310.

56 J. F. BOEHMER, Regesta Imperii, V, nº 3.020 .
} 
que él reclamaba, pero el hecho de que ya no se tengan noticias de réplicas por parte castellana, mientras que en contrapartida Fadrique permanecía al lado de su tío en una posición que se puede considerar privilegiada, invita a sospechar que esta reclamación de la herencia de Beatriz fue ante todo una excusa, tanto para acercarse a Federico como para legitimar frente al papa la presencia del infante casteliano en la corte imperial.

El infante Fadrique participó al lado de su tío en el conflicto que enfrentó a éste con las ciudades lombardas y con el papado, y precisamente en una fase caracterizada por la creciente radicalización del mismo, que culminó en la deposición de Federico como emperador en el concilio de Lyon de 1245. No obstante precisamente en el momento más difícil de la carrera política del emperador, el infante Fadrique optó por abandonarle para pasarse al bando de sus enemigos, sin que resulte posible determinar en qué medida esta decisión pudo estar determinada por la deposición formal de Federico II, que fue proclamada públicamente por el papa Inocencio IV en el referido concilio el día 17 de julio. En efecto en la reunión celebrada por el emperador en Verona en junio de 1245 para hacer sombra al recién convocado concilio de Lyon estuvo todavía presente Fadrique junto con algunos de los más fieles seguidores de Federico II, como por ejemplo el arzobispo de Salzburgo o Rodolfo de Habsburgo, futuro rey de romanos ${ }^{57}$. El 8 de julio la reunión de Verona quedó disuelta y el séquito imperial se dirigió hacia el oeste, al parecer con el objeto de acercarse hacia el papa. En Turín no obstante Federico II se enteraría de su deposición, y como consecuencia regresó hacia Cremona, produciéndose en el transcurso de este viaje la huida de Fadrique a la ciudad de Milán, el principal baluarte de la oposición política a Federico 11 en Italia ${ }^{58}$. En ese mismo mes de julio éste escribía a Fernando III manifestándole su disgusto por el que consideraba comportamiento ingrato del infante, $y$, para que no tuviese dudas sobre el carácter traicionero de la huida de su hijo, le pedía que averiguase la verdad interrogando a quienes iban a llevarle la carta, que eran antiguos compañeros del infante ${ }^{59}$.

Lamentablemente desconocemos la suerte de Fadrique después de su huida a Milán, y por ello no podemos determinar si al abandonar a Federico 11 buscaba escapar a los peligros de la vida política italiana para

57 Vid. F. W. SchIRRMACHER, Kaiser Friedrich der zweite, Göttingen, 1965, vol. 4, p. 138.

58 ibid. pp. 147 y ss. Recoge una noticia de los Annales Placentinos que reza así "lnterea filius regis qui cum eo erat fugit Mediolanum". Vid. también las referencias que proporciona J. F. BOEHMER, en Regesta Imperii.

59 J. F. BOEHMER, Regesta Imperii, V, n 3.491. 
regresar lo más pronto posible a Castilla, o por el contrario deseaba continuar en el escenario italiano, solo que esta vez apoyando al papa y a las comunas lombardas. A falta de pruebas documentales toda hipótesis explicativa ha de tener un fuerte componente especulativo, $y$, teniendo en cuenta la posterior trayectoria personal de Fadrique, no hay razón para presumir que las explicaciones que a nosotros nos puedan parecer más lógicas tengan necesariamente mayor garantía de veracidad. En cualquier caso lo que sí es seguro es que Fadrique en algún momento posterior a julio de 1245 regresó a Castilla, puesto que hay documentos que registran su presencia, pero no hay que olvidar que este regreso se produjo tras una larga ausencia, que algunos autores como Ballesteros no han sabido valorar adecuadamente ${ }^{60}$.

Esta primera estancia italiana del infante Fadrique sirvió por lo demás para introducir a la familia real castellana en el mundo de la gran política europea del momento, familiarizando a al menos algunos de sus miembros con el principal conflicto que entonces se estaba ventilando en el seno de la comunidad cristiana occidental, el del papa contra el emperador, y por extensión contra todo el linaje Staufer. Y teniendo en cuenta este precedente se puede explicar mejor la posterior reincorporación del propio infante Fadrique, esta vez en compañía de su hermano Enrique, a las últimas fases de este confficto, a las que vamos a dedicar nuestra atención a continuación.

\section{LOS INFANTES CASTELLANOS COMO ALIADOS DE LOS STAUFER EN LA ÚLTIMA FASE DEL CONFLICTO CON EL PAPADO Y LOS ANGEVINOS}

La intervención del infante Enrique, hermano de Alfonso $X$, en la política italiana en los últimos años de la década de 1260 resulta un hecho bien conocido tanto para la historiografía medievalista europea como para

60 Algunas de las referencias documentales sobre la presencia del infante Fadrique en Castilla las proporciona A. Ballesteros BeretTA, Alfonso $X$ el Sabio, El Albir, Barcelona, 1984. Este autor recoge la noticia de la llegada de Fadrique a Italia en 1240 a la edad de 17 años, pero da a entender que, al no haber obtenido del emperador satisfacción para sus pretensiones al ducado de Suabia, desistió de pasar a Alemania, regresando pronto a Castilla, para tomar parte junto con su padre en las conquisas contra la «morisma» (pp. 270-1). Este autor participa de la idea, muy arraigada en la tradicional historiografía hispana, de que el ducado de Suabia era un bien patrimonial que a Fadrique le correspondía heredar de su madre, y si no a él al menos al primogénito Alfonso. Vid. pp. 52 y 271 (Aqui afirma que Alfonso podia alegar mejor derecho al ducado que Fadrique). 
la española, en particular a lo que se refiere a su elección como senador romano en 1267 , y a su participación junto a Conradino en la batalla de Tagliacozzo de 1268, donde ambos fueron capturados por Carlos de Anjou ${ }^{61}$. No obstante un hecho menos tenido en cuenta, en particular por la historiografía española, es que el hermano de Enrique, el infante Fadrique, también fue un protagonista destacado de la historia italiana de estos años, y que la militancia de los dos hermanos no tuvo lugar siempre en el mismo bando.

El punto de partida para las intervenciones en Italia de los dos hermanos no fue sin embargo el reino de Castilla, del que ambos salieron exiliados en circunstancias no muy claras, sobre todo en el caso de Fadrique ${ }^{62}$, sino el emirato musulmán de Túnez, en el que los dos pasaron unos cuantos años al servicio del emir como jefes de tropas mercenarias ${ }^{63}$. La oportunidad para intervenir en la política italiana se produjo cuando Carlos de Anjou, hermano de Luis IX de Francia, fue designado por el papa para ocupar el trono siciliano, y en su intento de hacerse con la posesión efectiva del mismo chocó con el hijo bastardo de Federico II, Manfredo, quien se había hecho coronar rey de Sicilia en 1258. Precisamente a este príncipe del linaje Staufer, que en tantos aspectos había heredado el carácter de su padre Federico II, fue a quien el infante Fadrique acudió a auxiliar con sus tropas desde Túnez, participando con ellas en la batalla de Benevonto contra Carlos de Anjou, en la que éste resultó triunfador y

61 Entre la numerosa bibliografía referente a este asunto destacaríamos. G. DEL GIUDICE, Don Arrigo infante di Castiglia, Nápoles, 1875. P. HERDE, "Die Schlacht bei Tagliacozzo" en Zeitschrift für bayerische Landesgeschichte, 25 (1962), pp. 679 y ss. De este mismo autor Karl. I. von Anjou, Stuttgart, 1979, pp. 51 y ss. De gran interés resulta K. HAMPE, Geschichte Konradins von Honenstaufen, Innsbruhk, 1894. Entre las obras escritas en castellano la que aporta más datos es la de A. Ballesteros Beretta, Alfonso X... Esta obra presenta el problema de que no indica fuentes documentales, y quizás se limitó a tomar noticias de autores extranjeros, aunque en algunos puntos llega a corregir a éstos cuando malinterpretaron las fuentes castellanas, como es el caso de Busson, al que nos referiremos.

62 Sobre la huida del infante Enrique vid. A. BALLESteros, op. cit., pp. 262 y ss. Referencias a su inicial acogida por el rey de Inglaterra en Gascuña en la Chronica Maiora de Mateo Paris, en Rerum Britannicarum Medii Aevi. Scriptores (Rolls Series), 57, t. V, pp. 575-6 (Año 1256). Sobre la fecha y circunstancias de la huida de Fadrique A. BALLESTERos no consigue aportar datos, aunque sostiene que se produjo años después de la de su hermano. Vid. op. cit, pp. 192, 229 y 272. Ningún autor de los consultados aporta noticias aclaratorias en este sentido. R. STERNFELD se limita a afirmar que Fadrique y Enrique, huidos de Castilla por miedo a su hermano, entraron con sus hombres al servicio del emir de Túnez. Vid. su obra Ludwigs des Heilegen Kreuzzug nach Tunis 1270 und die Politik Karls I. von Sizilien, Berlin, 1896, p. 78.

63 El infante Enrique estuvo reclutando tropas en Gascuña a partir de julio de 1259 para ponerse al servicio del emir de Túnez en su lucha contra los almohades. Vid. A. Ballesteros, op. cit. p. 263. Resulta de momento imposible determinar cuándo Fadrique se incorporó a su lado al frente de estas tropas mercenarias. $\mathrm{Cf}$. nota anterior. 
Manfredo halló la muerte ${ }^{64}$. Las fuentes documentales no aclaran cómo entró en contacto el infante Fadrique con su lejano pariente Manfredo, pero en cualquier caso hay que tener en cuenta que el parentesco no pudo ser el factor decisivo que le movió a intervenir en el conflicto del lado de éste, puesto que el otro contrincante, Carlos de Anjou, estaba igualmente emparentado con él por parte de su madre, Blanca de Castilla, hermana de la abuela de Fadrique, la reina Berenguela. Determinar por otra parte si pudieron ser unas hipotéticas inclinaciones progibelinas las que inspiraron su actuación, equivale a adentrarse en el terreno de las especulaciones, aunque es cierto que en sus actuaciones políticas posteriores este infante continuó defendiendo la causa de los Staufer, y por consiguiente la de los gibelinos. Teniendo en cuenta que había permanecido largo tiempo en la corte de Federico II, en la fase crucial de la lucha de éste contra el papado, se podría explicar esta supuesta orientación políti$\mathrm{ca}$, pero el hecho de la huida a Milán en julio de 1245 no encaja en esta línea argumental, y por consiguiente consideramos muy improbable que la política italiana de Fadrique respondiese a la asunción de un programa político bien definido, sino que más bien sería el resultado de la adaptación a circunstancias concretas en busca del provecho y el medro personal. Sternfeld se expresa incluso en términos más radicales e interpreta la actuación de Fadrique al servicio de Manfredo como la de un simple jefe de mercenarios que trabajaría por dinero ${ }^{65}$.

Sea como quiera, la derrota de Benevento de 1266 llevó a Fadrique otra vez a territorio tunecino, hasta que de nuevo desde Italia se requirió su ayuda militar para la lucha contra los angevinos. Su hermano el infante Enrique mientras tanto había militado en el bando contrario, dado que consta que había financiado con su dinero la campaña de Carlos de Anjou contra Manfredo, y ya desde el año 1266 se encontraba en negociaciones con el papado, que iban orientadas a conseguir la mano de la viuda y heredera de Manfredo, que tras la derrota de Benevento se encontraba en poder de Carlos de Anjou. El interés en casar con esta princesa radicaba en que como hija del príncipe de Epiro tenía ciertos derechos a la isla de Corfú, pero no sólo el infante Enrique de Castilla aspiraba a hacerse con el control de estos territorios sino que también el propio Carlos de Anjou alimentaba ésta y aún mayores ambiciones, y por ello terminó adelantándose al castellano, tomando él mismo a la princesa en matrimonio. Fue el primer agravio de Carlos de Anjou al infante

64 Vid. K. HAMPE, op. cit., p. 147.

65 R. STERnfeld, op. cit., pp. 78-9. 
Enrique, quien no obstante continuó negociando con él y con el papa, y por ello abandonó definitivamente Túnez en febrero de 1267, y acompañado por sus tropas, que comprendian unos 300 caballeros, pasó a instalarse en tierras angevinas. En mayo él y Carlos de Anjou acudieron a la corte papal a Viterbo, donde se negoció sobre la futura cesión de Cerdeña a Enrique, pero con el transcurso del tiempo se fue poniendo de manifiesto que Carlos de Anjou también aspiraba a anexionarse esta isla, como un elemento más de la herencia de Manfredo. Por consiguiente el infante Enrique, sintiéndose engañado por el ambicioso angevino, se preparó para dar un giro radical a su política, y una oportunidad excepcional en este sentido se la proporcionó el pueblo romano, que, después de haber triunfado en la ciudad una revuelta progibelina del popolo, le invitó a que aceptase el cargo de senador ${ }^{66}$.

De esta manera comenzó la fase "gibelina" de la trayectoria del infante Enrique en Italia, marcada por el deseo de tomar venganza de Carlos de Anjou, durante la cual sus orientaciones políticas volvieron a confluir con las de su hermano Fadrique, puesto que ambos se pusieron entonces al servicio de la causa de su pariente lejano Conradino, el nieto de Federico II, hijo único de Conrado IV ${ }^{67}$. La colaboración del infante Enrique con Conradino, a quien preparó en la ciudad de Roma una acogida propia de un emperador para mayor disgusto del papa, constituye un hecho bien conocido para la historiografía clásica y moderna, pero en contrapartida ha dado lugar a más controversias la valoración de la intervención de Fadrique a favor de este último representante del linaje Staufer.

En concreto esta intervención, que se tradujo en un desembarco de tropas en Sicilia en agosto de 1267, antes incluso por consiguiente de que Conradino partiese de Augsburgo camino de la península italiana, fue solicitada por los propios gibelinos italianos partidarios de Conradino, puesto que a comienzos de 1267 Conrado Capece, actuando en nombre de Conradino, se trasladó a Túnez para negociar con el emir sobre este asunto, aprovechando la buena disposición que los emires tunecinos siempre habian mostrado hacia los Staufer. Según Hampe fue de hecho el emir el verdadero promotor de la expedición del infante Fadrique a Sicilia, dando así a entender que éste actuó a título de simple jefe de mercenarios a su servicio, y no movido por una supuesta simpatía progibelina o afecto hacia

66 Nos basamos en K. Hampe, op. cit. y P. Herde, Karl / von Anjou...

67 Sobre Conradino vid. además de las obras ya citadas, la reciente de síntesis divulgativa de F. Geldnen, Konradin. Das Opfer eines grossen Traumes, Bamberg, 1970. 
el linaje Stauier, al que no hay que olvidar que también había socorrido en la batalla de Benevento ${ }^{68}$. Disconforme con este punto de vista se ha mostrado sin embargo Sternfeld, para quien el verdadero inspirador de la expedición de Fadrique fue su hermano Enrique, quien después de haber sido elegido senador romano contactaría directamente con Túnez, y contribuiría así decisivamente a que Fadrique se decidiese a contribuir personalmente a la empresa de la conquista de Sicilia para Conradino, satisfecho porque su hermano se hubiese pasado definitivamente al bando gibelino ${ }^{69}$.

Fueran cuales fuesen las razones que movieron a los dos hermanos a apostar por el nieto de Federico II, lo cierto es que se trató de una decisión con consecuencias muy negativas para ambos, y que en última intancia determinó que los dos se viesen forzados a abandonar para siempre la escena política italiana y regresar a Castilla, una vez conseguido el perdón de su hermano Alfonso X. En concreto el infante Enrique fue hecho prisionero por Carlos de Anjou después de Tagliacozzo, y permaneció en esta situación hasta el verano de 1291, cuando fue liberado por intervención del rey Eduardo I de Inglaterra, pudiéndose constatar documentalmente que en 1294 se encontraba de nuevo en Castilla ${ }^{70}$. Para entonces ya hacía años que había muerto su hermano Alfonso $X$, y por consiguiente no hubo lugar para la reconciliación entre ambos, pero ya antes incluso de la derrota de Tagliacozzo se habían hecho correr rumores de que el monarca castellano había perdonado a su hermano y estaba dispuesto a dotarle con tierras en Castilla ${ }^{71}, y$, después de ser hecho prisionero Enrique por Carlos de Anjou, Alfonso X se mostró consternado y ofreció cierto apoyo al partido gibelino que luchaba por la expulsión de los angevinos de Italia ${ }^{72}$.

\footnotetext{
68 K. HAMPE, op. cit., pp. 189 y ss.

69 R. Sternfeld, op. cit., p. 81.

70 Nos basamos en P. SEGL, Voz "Heinrich el Senador (Arrigo)" en Lexikon des Mittlealters, IV, Múnich-Zúrich, 1989, pp. 2.059-60.

${ }_{71}$ Vid. K. HAMPE, op. cit., pp. 204-5. Considera este autor que esta noticia, que se hizo circular en la curia pontificia a fines de 1267, se difundió con el objetivo de apartar a Enrique de Italia. Llama la atención que por estas mismas fechas, hacia diciembre de 1267, gibelinos toscanos atacaron al embajador enviado por Alfonso X a la curia pontificia, el obispo de Silves, y le causaron la muerte. HAMPE considera que este crimen pudo haberse cometido con consentimiento del propio Enrique (Ibid. p. 204)

72 Vid. A. Busson, Die Doppelwahl des Jahres 1257 und das römische Königtum Alfons $X$ von Castilien, Münster, 1866, pp. 83 y ss. Constata este autor que tras la derrota de Conradino, Alfonso $X$ manifestó una clara oposición a los angevinos, y se convirtió en el punto de referencia fundamental de la oposición gibelina. No aporta sin embargo noticias que revelen que Alfonso $X$ trabajó activamente por conseguir la liberación de su hermano.
} 
El regreso a Castilla de Fadrique se produjo mucho antes. En efecto, éste pudo resistir en Sicilia unos cuantos meses después de la batalla de Tagliacozzo, que tuvo lugar en el continente, pero a medio plazo la resistencia en la isla se demostró inviable, por lo que tanto él como otros destacados gibelinos terminaron buscando refugio en Túnez. Es posible que desde allí planeasen nuevos ataques contra las posiciones angevinas en el sur de Italia, pero Carlos de Anjou con ocasión de la cruzada de su hermano Luix IX de Francia contra Túnez consiguió que en las negociaciones de paz se incluyese una cláusula por la que el emir se comprometía a expulsar de sus dominios a los cabecillas gibelinos que allí habían encontrado refugio, es decir, el infante Fadrique y Federico Lancia ${ }^{73}$. Y fue por esta razón por la que Fadrique se vio forzado a regresar a Castilla, donde ya aparece confirmando privilegios rodados muy a comienzos de $12722^{74}$. Dado que desconocemos las circunstancias en que se produjo su abandono del reino muy a fines de la década de 1250 o comienzos de la de 1260 , no podemos afirmar si a su regreso a Castilla le precedió una obtención de perdón regio, pero en cualquier caso su reincorporación a la vida política castellana se produjo sin aparentes dificultades, hasta que en 1277 tuvo lugar su repentina caída en desgracia, que arrastró también a su yerno el señor de Cameros, y dio lugar a que ambos fuesen ejecutados por orden regia ${ }^{75}$.

La prisión del infante Enrique tras Tagliacozzo, y la huida poco después del infante Fadrique a Túnez, no pusieron sin embargo fin a la participación castellana en los asuntos de Italia, aunque en honor a la verdad hay que advertir que en la actuación política de estos dos individuos no hay razones para ver una manifestación del interés de la monarquía castellana por los asuntos italianos, ya que ningún indicio apunta a hacer pensar que ambos actuasen en connivencia con su hermano Alfonso X. Por

73 Vid. R. Sternfeld, op. cit. A. BALLesteros llama la atención con razón sobre la inexactitud de las noticias cronísticas que refieren la presencia del infante Fadrique en Castilla hacia 1269, año en que se produjo su paso de Sicilia a Túnez, huyendo de los angevinos. Vid. su obra Alfonso $X \ldots$ pp. 428, 433, 486 y 492. También llama la atención sobre el error en que incurre, malinterpretando una fuente castellana, A. Busson, quien afirma que Fadrique estaba en Castilla en 1269. Vid. Die Doppelwahl... p. 84. El desmentido de Ballesteros en op. cit. p. 547. No advierte sin embargo este autor que Fadrique tuvo que abandonar Túnez porque así se estableció en las condiciones de paz, por lo que es prácticamente seguro que no utilizó la obra de STERNFELD.

74 A. Ballesteros, op. cit. pp. 546 y ss. Dado que la paz entre los cruzados y el emir de Túnez se negoció a fines de 1270, cabe presumir que Fadrique regresaría a Castilla en el transcurso de 1271.

75 Sobre este episodio del año 1277, que Moxó califica como el más sombrío del reino, Vid. A. Ballesteros, op. cit. 
otra parte su militancia en los dos bandos, angevino y gibelino, no permite explicar su intervención en Italia como resultado de un hipotético sentimiento de solidaridad hacia sus parientes Staufer, que podríamos presumir más arraigado en el infante Fadrique, si no fuese porque nos consta que éste abandonó a su tío Federico ll en uno de los momentos más críticos de su trayectoria política para pasarse al enemigo, representado por las ciudades lombardas y el papa. En consecuencia es bastante probable que en ellos privase el móvil propio de los mercenarios, pero sin ninguna duda su condicón de hijos de Beatriz de Suabia debió despertar hacia ellos simpatías, que de otro modo hubiesen estado ausentes. Y por supuesto fue también esta condición la que permitió a Alfonso $X$ entrar de lleno en la política italiana, como hasta entonces no lo había hecho ningún monarca castellano.

\section{LA POLITICA IMPERIAL E ITALIANA DE ALFONSOX}

Al analizar las consecuencias a largo plazo del matrimonio de Fernando III con Beatriz de Suabia no se puede dejar de hacer una breve referencia a esta cuestión, que es una de las más abordadas de cuantas hemos tenido en cuenta en el presente trabajo, por lo que sólo nos vamos a referir a ella de forma somara.

El interés de Alfonxo $X$ por los asuntos del imperio se manifestó ya antes de la muerte de Guillermo de Holanda, y de que los embajadores de la ciudad de Pisa le familiarizasen por primera vez con la idea de poder convertirse en emperador ${ }^{76}$. En efecto ya en vida de su padre Fernando III, Alfonso intercambió correspondencia con el emperador Federico II, a quien tal vez llegase a acudir para que apoyase su candidatura para la sucesión en Provenza, donde finalmente sin embargo consiguió imponerse su pariente y rival Carlos de Anjou ${ }^{77}$. A la muerte de Conrado IV, Alfonso

76 Vid. A. Busson, Die Doppelwahl..., pp. 19 y ss.

77 Vid. E. WINKELMANN, Acta Imperii Inedita seculi XIII. Urkunden und Briefe zur Geschichte des Kaiserreichs und des Kónigreichs Sicilien in den Jahren 1198 bis 1273, Innsbruck, 1880. Doc. n. 387, carta de Federico II al infante Alfonso, fechada en Nápoles en julio de 1246, en la que le informa sobre varios acontecimientos de la política italiana, y sobre la victoria conseguida en Alemania por su hijo Conrado contra el landgrave de Turingia, elegido rey por el partido papal. Vid. también de este mismo autor Acta Imperii Inedita... in den Jahren 1200-1400, Innsbruck, 1885, doc. $n^{\circ} .47$, pp. 51-2. Documento fechable en torno a los años 1245-6 en el que Federico II responde a los deseos manifestados por Alfonso de Castilla en relación al asunto de la condesa de Provenza. Según Winkelmann la carta seria escrita tras la muerte de Ramón Berenguer de Provenza el 19-VIII-1245, y quizás tras la boda de su heredera Beatriz con Carlos de Anjou el 191-1246. Sobre este asunto pueve verse. P. HERDE, Karl l. von Anjou. 
$X$, convertido ya en rey de Castilla, protagonizó un nuevo episodio de intervención en los asuntos del imperio, esta vez centrado en Alemania, al pretender la sucesión al ducado de Suabia.

En rigor Alfonso $X$ tenía tan pocos derechos a la sucesión al ducado de Suabia como años antes su hermano Fadrique, pero paradójicamente en esta ocasión el papa Alejandro IV llegó a ponerse abiertamente de su lado, puesto que el 4 de febrero de 1255 despachó desde Nápoles una carta dirigida a los obispos, abades y príncipes de Suabia para que apoyasen al rey de Castilla en su empresa de adquisición del ducado suabo ${ }^{78}$. No obstante hay suficientes motivos para dudar que este papa contemplase de hecho la posibilidad de que el rey castellano se convirtiese efectivamente en duque de Suabia, y en efecto también su antecesor Inocencio IV había seguido una política manifiestamente contradictoria en este asunto, al reconocer por un lado el derecho a la sucesión al ducado a Alfonso, entonces todavía príncipe, y luego ofrecérselo a Guillermo de Holanda, el rival del auténtico duque, Conrado IV ${ }^{79}$. En concreto Alejandro IV, según el punto de vista de Hampe, habría alentado las pretensiones a Suabia del rey castellano para así presionar indirectamente sobre los duques bávaros que tenían en su poder a Conradino, a fin de que se movilizasen para que éste se quedase con la herencia suaba, y renunciase en contrapartida a sus pretensiones a Sicilia ${ }^{80}$.

Alfonso $X$ por lo demás no hizo esfuerzos apreciables para conseguir que sus pretensiones sobre Suabia alcanzasen una cierta traducción en hechos positivos, a pesar de que fue en esta región de Alemania donde su candidatura imperial encontró al parecer más simpatizantes. En efecto Hampe llama la atención sobre el hecho de que fueron príncipes suabos, el obispo de Constanza y el abad de Sankt Gallen, los que acudieron a comunicar a Alfonso $X$ su elección por algunos de los príncipes alemanes en 1257, después de la muerte de Guillermo de Holanda. Y según este mismo autor estos embajadores al tiempo que le comunicaban su elección como rey de romanos, le manifestaron su reconocimiento como duque de Suabia ${ }^{81}$. La reacción del monarca castellano ante este reconocimien-

\footnotetext{
78 Vid. K. Rondenberg (Ed.) Epistolae Saeculi XIII e regestis Pontificum Romanorum, t. III, Berlin, 1894, doc. 372, pp. 336-7.

79 Carta de Inocencio IV a Alfonso, fechada en Lyon, 3-V-1246, en la que le promete apoyarle en sus pretensiones a la herencia de su madre, centradas en torno al ducado de Suabia en $\mathrm{K}$. Rodenberg (Ed.) Epistolae..., t. II, Berlín, 1887, doc. nº. 180, pp. 136-7. Para más detalles sobre el ducado de Suabia remitimos a H. MAURER, op. cit.

8. K. HAMPE, op. cit., pp. 10 y ss.

81 lbid. p. 18.
} 
to parece sin embargo que se limitó a adoptar en su larga y pomposa serie de títulos el de duque de Suabia, y por ello el joven Conradino, último representante del en otro tiempo todopoderoso linaje Staufer, no encontró en él un verdadero rival en territorio suabo, y hasta tal punto esto fue así que el propío papa Urbano IV llegó a reconocerle a Conradino en una de sus cartas el título de duque de Suabia ${ }^{82}$.

La falta de interés de Alfonso X por la política alemana ha sido puesta de manifiesto por la mayor parte de los autores que han analizado su «política imperial» ${ }^{83}$, y aunque es cierto que mantuvo algunos contactos políticos con algunos príncipes alemanes, entre los que se encontraban parientes suyos como el duque de Brabante ${ }^{84}$, su interés se centró en la península italiana, que si bien tampoco fue visitada personalmente por él, al menos sí recibió contingentes militares procedentes de Castilla para reforzar a sus partidarios gibelinos.

Los primeros contactos efectuados por Alfonso $\mathrm{X}$ en Italia para promocionar su candidatura imperial dieron lugar a una alianza con el célebre tirano Ezzelino de Romano, que no obstante tuvo pocas consecuencias debido a la muerte de este último ya en $1259^{85}$. De hecho en esta primera fase la presencia todavia de representantes del linaje Staufer en Italia representaba un importante freno para los avances de la candidatura imperial de Alfonso $X$ en territorio italiano, puesto que el partido gibelino continuaba viendo en los Staufer a sus líderes naturales, mientras que el partido contrario, el liderado por el papa y luego también por Carlos de Anjou, cada vez se fue manifestando más reacio a la candidatura alfonsina, sobre todo después de los devaneos con Ezzelino.

Hasta la batalla de Tagliacozzo por consiguiente la figura de Alfonso $\mathrm{X}$ se mantuvo en un segundo plano en el escenario italiano, en el que en contrapartida alcanzaban mayor protagonismo sus hermanos Enrique y Fadrique. A partir de entonces la muerte de Conradino, la prisión de

82 Ibid. p. 55. Vid. también H. MaURER, op. cit., p. 276. Pone de manifiesto que Conradino nunca fue investido formalmente con el ducado de Suabia, que era un feudo del imperio, por el rey Ricardo de Cornmualles, a pesar de las reiteradas promesas que le hicieron los papas Inocencio IV y Alejandro IV, y el propio Ricardo.

83 Entre otras obras hay que destacar A. BuSSON, op. cit. C.J. Socarras op. cit. A. Ballesteros, "Alfonso $X$ de Castilla y la corona de Alemania" Revista de Archivos, Bibliotecas y Museos, 34 (1916), pp. 1-23, y 187-219; 35 (1916), pp. 223-242; 39 (1918), pp. 142-162 y 40 (1919), pp. 467-490. Y P.E. Schramm, «Das Kastilische Königtum in der Zeit Alfons des Weisen (1252-1284)" en Festschrift Edmund E. Stengel, Münster-Köln, 1952, pp. 385-413.

${ }^{84}$ Vid. A. Busson, op. cit., pp. 66 y ss.

85 Ibid, pp. 75-6. 
Enrique y la huida de Fadrique dejaron el escenario libre al monarca castellano, quien intensificó entonces sus contactos con los gibelinos italianos, particularmente lombardos. Ya en enero de 1271 Ubertino de Lando se convirtió en vasallo suyo, y en el transcurso de este año se ejecutó el proyecto de matrimonio de una de sus hijas con un poderoso noble lombardo, el marqués Guillermo de Monferrato, uno de los cabecillas de la oposición gibelina en Italia contra Carlos de Anjou ${ }^{86}$. En adelante los contactos políticos de Alfonso $X$ con su yerno lombardo fueron muy intensos, y llegaron a traducirse en el envio de refuerzos militares, si bien en un momento en que las perspectivas para la candidatura imperial de Alfonso $X$ se habían deteriorado de tal forma que ésa resultaba ya casi quimérica.

En efecto, los principales envíos de tropas castellanas a Italia tuvieron lugar en 1274, después por consiguiente de la muerte de Ricardo de Cornualles, el rival de Alfonso $X$ a la candidatura imperial, y de la elección por los príncipes alemanes de un nuevo rey de romanos en la persona de Rodolfo de Habsburgo. Para entonces puede que el prestigio de Alfonso $\mathrm{X}$ fuese todavía grande entre los gibelinos, pero, aunque Rodolfo de Habsburgo no parecía muy dispuesto a trasladarse a Italia para imponer su candidatura, las perspectivas de victoria para el monarca castellano en Italia eran mínimas, porque jugaba en su contra la determinación del papa Gregorio $X$ de imponer a Rodolfo como rey de romanos. $Y$ éste no cesó hasta que consiguió que Alfonso $X$ renunciase a sus derechos en Beaucaire en 1275 , poniendo así fin a la intervención castellana en los asuntos del Imperio, y de Italia muy en particular.

En adelante la monarquía castellana cedió el protagonismo en este ámbito a la catalano-aragonesa, convertida en principal rival de los angevinos en Italia. Y curiosamente también fue con miembros de la familia real catalano-aragonesa con la que las dinastías alemanas que gobernaron en el imperio bajomedieval concertaron matrimonios ${ }^{87}$. Castilla se

86 Ibjd, pp. 89 y ss.

87 Existe una bibliografia relativamente abundante sobre esta cuestión, en lengua alemana. De H. FINkE destacan "Die Ehe Konrads von Reischach mit der letzten Königin von Mallorka" Zeitschrift für die Geschichte des Oberrheins, Nueva Serie 19 (1904), pp. 265-283. Y "Aragonesisch-sicilische Beziehungen zum bayerisch-ptälzischen Hause im 14. Jahrhundert» ibid. 39 (1926), pp. 499-514. Y "Zur Korrespondenz der deutschen Könige und Fürsten mit den Herrschern Aragons im 14. und 15. Jahrhundert” en Gesammelte Aufsätze zur Kuiturgeschichte Spaniens, 5 (1935). De R. NEUMANN interesa su tesis doctoral, Die politischen Beziehungen zwischen dem deutschen Reich und Aragonien in der Zeit von Rudolf von Habsburg bis Ruprecht von der Pfalz, Friburgo de Brisgovia, 1914. De H. von ZeIssberg, Elisabeth von Aragonien, Gemahlin Friedrichs des Schönen von Oesterreich, Viena 1898. 
La monarquia castellana y los Staufer. Contactos políticos y diplomáticos en los...

alejó tanto de Alemania como de Italia, de forma que en la Baja Edad Media la intensificación de los contactos políticos con estos ámbitos que se inició en época de los Staufer no tuvo continuidad, hasta que la tendencia se invirtió en época de los Reyes Católicos. 